\title{
Comunicação pública e campanhas de amamentação: representações da mulher-mãe
}

Public communication and breastfeeding campaigns: representations of the woman-mother

Comunicación pública y campañas de lactancia materna: representaciones de la mujer-madre

\section{(9) Amanda Braga Silveira}

- Mestra em Comunicação e Informação pela Universidade Federal do Rio Grande do Sul (UFRGS).

- Bacharela em Comunicação Social com habilitação em Relações Públicas pela UFRGS.

- Pesquisadora do Grupo de Pesquisa em Comunicação Organizacional, Cultura e Relações de Poder (GCCOP) da UFRGS.

- E-mail: rp.asilveira@gmail.com

9. Rudimar Baldissera

- Doutor em Comunicação Social pela Pontifícia Universidade Católica do Rio Grande do Sul (PUCRS).

- Mestre em Comunicação/Semiótica pela Universidade do Vale do Rio dos Sinos (Unisinos).

- Bacharel em Relações Públicas Pela Universidade de Caxias do Sul (UCS).

- Professor associado do Departamento de Comunicação da Faculdade de Biblioteconomia e Comunicação (Fabico) da UFRGS.

- Professor e pesquisador do Programa de Pós-Graduação em Comunicação (PPGCOM) da UFRGS CAPES.

- Líder do Grupo de Pesquisa em Comunicação Organizacional, Cultura e Relações de Poder (GCCOP) da UFRGS - www.ufrgs.br/gccop

- Bolsista de Produtividade do CNPq.

- E-mail: rudimar.baldissera@ufrgs.br 


\section{Resumo}

Neste artigo problematizamos os processos de comunicação pública realizados pelo Ministério da Saúde, a partir das representações da mulher-mãe percebidas pelas participantes do Estudo LINDA-Brasil na sua Cartilha para a mulher trabalhadora que amamenta. Para isso, são acionados aportes teóricos sobre dimensões culturais e históricas da noção de "representações da mulher-mãe" e processos de comunicação pública, além de dados da pesquisa empírica realizada por Silveira, que compreendeu a realização de um grupo focal com participantes do Estudo LINDA-Brasil.

\section{PALAVRAS-CHAVE: COMUNICAÇÃO PÚBLICA•CAMPANHAS DE AMAMENTAÇÃO.}

\section{Abstract}

In this article we problematize the processes of public communication carried out by the Ministry of Health, from the representations of women-mother perceived by participants of the LINDA-Brazil Study in their Primer for working women who breastfeed. For this, theoretical contributions about cultural and historical dimensions of the notion of "representations of the woman-mother" and processes of public communication are triggered, as well as data from the empirical research conducted by Silveira, which comprised in the realization of a focus group with participants of the LINDA-Brazil Study.

KEYWORDS: PUBLIC COMMUNICATION • BREASTFEEDING CAMPAIGNS.

\section{Resumen}

En este artículo, problematizamos los procesos de comunicación pública llevados a cabo por el Ministerio de Salud que se basan en las representaciones de mujeres-madres percibidas por las participantes del Estudio LINDA-Brasil en su Manual para mujeres trabajadoras que amamantan. Para ello, se activan contribuciones teóricas sobre las dimensiones culturales e históricas de la noción de "representaciones de la mujer-madre" y los procesos de comunicación pública, además de los datos de la investigación empírica realizada por Silveira, que comprendió la realización de un grupo focal con participantes del Estudio LINDA-Brasil. 


\section{SOBRE O ESTUDO}

0 aleitamento materno é hoje intensamente estimulado pelas organizações internacionais e por políticas públicas nacionais como estratégia de saúde pública que influencia, decisivamente, na redução das taxas de morbimortalidade infantil e na promoção da saúde da criança. Nesse sentido, ao longo das últimas duas décadas, o Ministério da Saúde brasileiro intensificou a produção de materiais de comunicação voltados à educação em saúde orientados à temática.

Conforme aponta um estudo realizado por Kalil, em 2015, somente entre 2007 e 2010 o órgão produziu um volume significativo de documentos oficiais sobre o tema, o que revela a importância crescente que a informação e a comunicação têm adquirido no âmbito da saúde da criança em nosso país. É nesse contexto que este estudo se insere, a partir da pesquisa realizada por Silveira (2018) sobre representações da mulher-mãe na/pela Cartilha para a mulher trabalhadora que amamenta (produzida e veiculada pelo Ministério da Saúde).

Para refletirmos sobre a circulação dessas representações em perspectiva da comunicação pública, importa destacarmos, desde aqui, que a comunicação é compreendida como "processo de construção e disputa de sentidos" (Baldissera, 2000, p. 21). Ainda conforme Baldissera (2008), essa concepção salienta a centralidade da significação para os/nos processos comunicacionais e evidencia sua complexidade. Nessa direção, as Campanhas de Aleitamento Materno produzidas pelo Ministério da Saúde vão muito além de publicizar ou divulgar ações e serviços. Vistas como materializações discursivas, têm potência para influenciar na configuração da cultura, naturalizando e (re)afirmando modos de ser e estar no mundo. Diante disso, neste artigo temos 0 objetivo de problematizar os processos de comunicação pública realizados pelo Ministério da Saúde, a partir das representações da mulher-mãe percebidas pelas participantes do Estudo LINDA-Brasil na sua Cartilha para a mulher trabalhadora que amamenta.

\section{REPRESENTAÇÕES DA MULHER-MÃE}

O entendimento de cultura como um conjunto de "significados compartilhados" é a origem do raciocínio de Hall (2016, p. 17) sobre o funcionamento da linguagem como processo de significação. Assim, segundo o autor, a "linguagem é um dos 'meios' através do qual pensamentos, ideias e sentimentos são representados numa cultura" (Hall, 2016, p. 18; grifos no original), posto que considera a cultura como o local de criação e troca de significação em um grupo e/ou sociedade.

É nesse sentido, portanto, que a noção de representação é fundamental para este trabalho, pois que as representações são centrais nos processos de produção e circulação de sentidos nas interações estabelecidas entre os indivíduos que constituem um grupo cultural, uma sociedade. Os usos que fazemos das coisas, o que dizemos, pensamos e sentimos sobre elas - como as representamos - exercem-se em perspectiva de conformar sua significação. Mediante interações o mundo é estruturado em representações, a significação é construída, transacionada, intercambiada e, mesmo, instituída. Cabe ressaltar que, muitas vezes, essas representações passam por complexos processos de naturalização de concepções de mundo exigindo ser admitidas e assumidas pela sociedade, não mais como representações, mas como a 'verdade'.

Além disso, o exercício da linguagem sempre atualiza relações de poder de modo que nas interações que os sujeitos estabelecem, não apenas constroem significação de mundo, mas, fundamentalmente, procuram instituir a significação que melhor atenda os interesses dos grupos político-socioculturais que representam. Nesse entendimento, ocupar o lugar de fala é também apoderar-se para dizer de si em relação aos outros, para dizer das representações que devem ser validadas como legítimas e quais devem ser desprezadas e descartadas. 
Nessa perspectiva e considerando o recorte deste estudo, podemos afirmar que também são essas práticas de significação linguística e cultural, sempre orientadas por desejos de poder, que produzem e fazem circular os significados de mulher, mãe e nutriz. Essas representações são instituídas como lentes a serem empregadas pelas mulheres para entenderem suas experiências, pois que prescrevem e definem o que elas devem ser, fazer e sentir, e, na perspectiva deste estudo, como mulheres trabalhadoras que amamentam (Meyer, 2003). Assim, apesar de as variadas representações da mulher-mãe, culturalmente criadas e compartilhadas na sociedade, produzirem sentidos que funcionam competindo entre si, deslocando, acentuando ou suprimindo convergências, conflitos e divergências entre diferentes discursos e identidades, de fato, são apenas algumas delas que, dentro de determinadas configurações de poder, acabam se revestindo de autoridade científica e/ou se transformando em senso comum, a tal ponto que deixamos de reconhecê-las como representações (Meyer, 2003) para assumi-las como sendo as 'verdadeiras' concepções.

É assim que uma dessas representações de mulher-mãe, numa espécie de naturalização, põe em suspenso seu caráter de representação para funcionar, num determinado contexto sócio-histórico e cultural, como sendo a melhor concepção ou a verdadeira mulher-mãe - a boa mãe - aquela que se transforma em referência não só nas Campanhas de Amamentação, mas também para as próprias mulheres, e a partir da qual outras mulheres são classificadas e valoradas. De acordo com Meyer (2003), as práticas de significação e os processos simbólicos, através dos quais os sentidos de mulher-mãe são produzidos e intercambiados exercem o poder de nomear, descrever, classificar, identificar e diferenciar, por exemplo, jeitos de ser mulher e mãe, portanto, exercem o poder de incluir, excluir e definir corpos, comportamentos, grupos e/ou mulheres individuais e, assim, demarcar os seus lugares sociais.

As pesquisas científicas sobre o aleitamento materno confirmam a singularidade do leite humano e trazem esclarecimentos sobre o processo da lactação. Contudo, a amamentação não se reduz apenas em fatos biológicos, pois que engloba dimensões construídas cultural, social e historicamente (Nakano, 2003). Nessa direção, trabalhos na área da história social que analisam a construção de significados do aleitamento materno e da maternidade através dos tempos, entre eles os de Badinter (2011), Silva (1990) e Costa (1999), indicam que as representações da mulher-mãe a partir da amamentação guardam relação com o lugar, a imagem social da mulher e a maternidade, e podem diferir em diferentes épocas e contextos sociais em razão de valores e interesses econômicos e políticos específicos.

Neste sentido, e partindo do mesmo entendimento que os demais autores, para Bosi\& Machado (2005) é importante reconhecer que o valor atribuído ao leite humano e para suas vantagens nutricionais e afetivas apresentam, nos dias de hoje, as mesmas flutuações na sua prática que se apresentaram ao longo da história, em diferentes sociedades. Isso porque a prática da amamentação, longe de significar um ato instintivo, natural, representa um hábito preso a determinantes sociais e às manifestações da cultura. As concepções e valores, incorporados pelo processo de socialização, influem na prática da amamentação tanto quanto 0 equilíbrio biológico e o funcionamento hormonal da mulher, ainda que o discurso hegemônico não o aceite (Bosi; Machado, 2005).

Logo, o aleitamento materno está, como assume Badinter (2011, p. 86), na essência de uma determinada filosofia de maternidade "que condiciona a situação da mulher e seu papel na sociedade". Nessa direção, conforme Kalil (2015), na maior parte dos discursos brasileiros e internacionais materializados por governos e organizações que atuam em prol da amamentação, ela vem sendo apresentada como uma prática "naturalizada" no sentido de um comportamento que é passado como incontestável ou a-histórico, ao qual se confere estatuto de "verdade" (Kalil, 2015, p. 50).

No entanto, essa afirmação que se faz a todas as mulheres que se arriscam na experiência da maternidade, tratando a prática do aleitamento materno como comportamento "instintivo" ou "natural" (Badinter, 2011), não foi unânime em outros momentos históricos e em distintas situações socioculturais, bem como não é vivenciado nos mesmos termos em diferentes classes dentro de uma única sociedade complexa (Kalil, 2015). Assim, ainda de acordo com Kalil (2015), os discursos proferidos e difundidos 
mundialmente, ao longo do último quarto do século XX, em prol do aleitamento materno, por governos, organizações nacionais e internacionais dedicadas à saúde vêm influenciando a consolidação de um processo identificado, na atualidade, como uma nova ideologia de maternidade que procura modular o comportamento da mulher em favor da amamentação, imputando-lhe culpa e responsabilidade pelo desmame precoce, que está associado de forma direta a agravos para a saúde de seu filho.

\section{PROCESSOS DE COMUNICAÇÃO PÚBLICA}

Desde a retomada do movimento em defesa do aleitamento materno, principalmente, a partir do último quarto do século XX, muitas razões foram usadas para defender a amamentação, "que vão desde as propriedades biológicas ímpares do leite humano até as questões de cunho econômico, capazes de impactar tanto a família como o Estado" (Almeida, 1998, p. 13). Estritamente em relação ao Estado, Almeida (1998, p. 71) alega que "os aspectos relacionados à saúde e à economia têm merecido lugar de destaque nas publicações. A adoção de políticas de promoção e apoio à amamentação é apresentada como uma estratégia supletiva de saúde pública". Diante disso, Kalil (2015) afirma que o Brasil vem investindo no aumento dos índices de aleitamento materno ao promover e imprimir em seus discursos oficiais os parâmetros e as orientações divulgadas pela Organização Mundial da Saúde (OMS) e pelo Fundo das Nações Unidas para a Infância (Unicef).

Nessa direção, e pensando o quanto a prática da amamentação sofre influências das estratégias de políticas públicas, tais como: quando o Ministério da Saúde recomenda em seus materiais educativos os períodos ideias de aleitamento (que duram até 2 anos), essa prática acaba tornando-se assunto de interesse público posto que, segundo Sartor e Baldissera (2016, p. 325), o interesse público constitui o princípio que, nas comunidades democráticas, "deve nortear a criação e a aplicação das leis, o desenvolvimento das políticas públicas, o direcionamento dos investimentos estatais, a veiculação de notícias pelos meios de comunicação e outras práticas relativas às instituições sociais que regulam, transformam ou informam a esfera da cidadania". Desse modo, conforme Pitta (2002), a comunicação pública torna-se tema estratégico ao tratarmos de políticas públicas, principalmente ligadas à área da saúde pública.

Cabe destacarmos aqui, que empregamos as noções de esfera pública, comunicação pública e opinião pública sob a perspectiva da teoria democrática deliberativa, a partir de autores como Gomes (2006), Esteves (2011) e Matos (2011). Nesse sentido, destacamos que por esfera pública compreendemos o espaço simbólico em que o público de cidadãos interage para debater temas de interesse público. Assim, a comunicação pública materializa-se para dar visibilidade a essas questões, bem como para a realização do debate e da crítica sobre elas. Nessa perspectiva, e de modo sucinto, mas suficiente para os objetivos desta pesquisa, a opinião pública "pode ser entendida como resultado (sempre provisório) do processo de comunicação pública que expressa um acordo coletivo, legítimo apenas na medida em que se constitui por meio do debate livre e inclusivo" (Sartor; Baldissera, 2016, p. 337; grifos no original).

Sob essa concepção, como práticas ideais de comunicação pública, destacamos: a) a visibilidade, definida por Esteves (2011), como a ação de tornar algo público: dar a conhecer opiniões, ideias, fatos, situações, pessoas - e pensando nos objetivos da Cartilha, direitos e modos de fazer; b) a crítica, que se fundamenta no posicionamento perante os temas, assuntos ou problemas presentes na comunicação pública, e que se dá através do exercício de juízos diante de diversas opiniões que foram objeto de publicização; e c) o debate, percebido como a parte que confere um sentido próprio à comunicação pública e encarregado de imprimir a essa comunicação uma orientação de caráter sobretudo racional, adotando um "valor de esclarecimento" no plano intelectual e uma "força de emancipação" no plano moral (Esteves, 2011, p. 197).

Desse modo, é o próprio debate, independente das instâncias e das instituições, que caracteriza a esfera pública (Gomes, 2006) e, de maneira extensiva, a comunicação pública. Dela também faz parte o cidadão desinstitucionalizado, ou seja, 
aquele que está nas praças e participa das conversações cotidianas - no caso desta pesquisa, as mulheres trabalhadoras que amamentam. Com propósitos políticos específicos ou não, esses cidadãos fazem uso do conjunto de argumentos postos a circular por governos, organizações, entidades da sociedade civil, mídia e até mesmo por indivíduos que compartilham mensagens e discutem alternativas na internet, pois que, segundo Matos (2011), a comunicação pública ocorre no campo que permeia a sociedade e o Estado e no qual uma pluralidade de vozes toma seu lugar.

Portanto, a fertilidade da comunicação pública também está no 'empoderamento' da sociedade para a participação. E os governos não podem se esquivar do papel de articuladores dos meios que favorecem a comunicação pública democrática e inclusiva, e devem ser chamados a gerenciar um conjunto de políticas para a efetiva participação dos distintos públicos, da sociedade. Isto é, pelo pressuposto de seu compromisso com o interesse público e considerando seu poder de ação, precisam ser os principais geradores da comunicação pública (Gil; Matos, 2013).

\section{SOBRE OS PROCEDIMENTOS METODOLÓGICOS}

Destacamos aqui, de modo objetivo, os procedimentos adotados para a coleta e análise dos dados. Conforme Silveira (2018), para a coleta de dados foi realizado um grupo focal com 7 mulheres que participam do Grupo de Intervenção do Estudo LINDA-Brasil, vinculado ao Centro de Investigação de Porto Alegre e que já realizou a Visita de Um Ano após a randomização. O Estudo LINDA-Brasil é um Estudo Multicêntrico de Mudanças Intensivas de Estilo de Vida: é um ensaio clínico, randomizado, multicêntrico, em que são recrutadas gestantes atendidas em unidades de atenção para Diabetes Mellitus Gestacional(DMG) no Sistema Único de Saúde (SUS), nas cidades de Curitiba, Fortaleza, Pelotas, Porto Alegre, Rio de Janeiro e São Paulo. São convidadas a participar do Estudo mulheres com 18 anos ou mais, entre a 32ª e 37ª semanas de gestação (Schmidt etal., 2016).

Tendo início em 2014, esse estudo epidemiológico objetiva investigar a eficácia de um programa de mudanças de estilo de vida para retardar ou prevenir o diabetes tipo 2, quando realizado após uma gravidez complicada por DMG. Nesse cenário, após o recrutamento e o nascimento do bebê, as mulheres passam pela coleta das medidas basais e, se forem elegíveis, seguem para o arrolamento ao ensaio clínico randomizado, no qual as participantes são designadas a um dos dois grupos de comparação: 1) Grupo Controle; recebe atendimento convencional com instruções atualizadas sobre a prevenção do diabetes; e 2) Grupo de Intervenção, recebe os mesmos pricipíos aplicados ao Grupo Controle e um suporte adicional, principalmente por telefone, além de um kit para extração do leite (Schmidt etal., 2016).

Nesse kit, a "Cartilha para a mulher trabalhadora que amamenta" (Brasil, 2015) é o principal material de promoção e apoio ao aleitamento materno usado para ajudar as participantes e a Equipe do Estudo LINDA-Brasil no esclarecimento de dúvidas. Além disso, a Cartilha (2015) (interesse desta pesquisa), que segundo o Ministério da Saúde tem como objetivo "dar algumas respostas" $(2015$, p . 4) às mulheres trabalhadoras sobre "como conseguir amamentar e, ao mesmo tempo, trabalhar fora de casa" (2015, p. 3), apresenta os direitos da trabalhadora que está amamentando, destaca a importância do aleitamento materno e orienta sobre como proceder para manter a amamentação após o retorno ao trabalho. Diante disso, a pesquisa foca-se nos relatos do grupo focal, dado que um dos componentes específicos da intervenção nesse grupo é o emprego da Cartilha.

Os relatos do grupo focal foram interpretados mediante Análise de Conteúdo (Bardin, 2011). Desse modo, com base em similaridades temáticas e pelo agrupamento de sequências de texto (STs), a categorização aconteceu em dois níveis temáticos. Assim, e a partir da percepção das participantes do Estudo LINDA-Brasil, apresentamos a grande categoria, seguida pelas subcategorias correspondentes e seus respectivos núcleos de sentido. A grande categoria: "Representações da Mulhermãe na Sociedade", desdobra-se em duas subcategorias: 1) "Mulher-mãe com Leite"; e 2) "Mulher-mãe Seca". Por sua vez, 
a subcategoria "Mulher-mãe com Leite", desdobra-se em dois núcleos de sentido relacionados: 2.a) "Mulher-mãe Frágil", que se trata da percepção dela sobre si mesma em relação a; 2.b) "Mulher-mãe Empoderada".

\section{REPRESENTAÇÕES DA MULHER-MÃE NA/PELA CARTILHA}

Neste subitem discorremos, objetivamente, sobre essas "Representações da Mulher-mãe materializadas na/pela Cartilha", conforme percepções das entrevistadas.

\section{Mulher-mãe com Leite}

Para Nakano (1996), a amamentação é um processo centrado na mulher e a maternidade é tradicionalmente concebida como principal elemento definidor da identidade feminina ao longo da história, de modo que o aleitamento materno se dá como atividade institucionalizada, com regras e condutas estabelecidas socialmente. Frente essa institucionalização e considerando a análise realizada, esta subcategoria abrange as percepções que as entrevistadas têm sobre a mulher-mãe que a qualificam como a mãe boa, ou seja, aquela que atende as representações compartilhadas pela sociedade, que cumpre com as regras e condutas pré-estabelecidas no coletivo.

Nessa direção, os núcleos de análise dessa subcategoria se deram pela força da expressão Mulher-mãe com Leite. Essa construção foi expressa repetidas vezes pelas participantes, principalmente quando questionamos sobre os significados de mulher, mãe e nutriz:

[...] A minha [ filha], se deixar, ela passa o dia todo na teta! [...] E eu acho uma coisa maravilhosa, porque tu imagina(sic), tu não poder dar de mamar pro (sic) teu filho, né? [...] E a gente tem leite!(E1)

Com orgulho, em suas falas reforçam que ainda têm ou tiveram leite, uma vez que essa representação da Mulher-mãe com Leite carrega em seus significados a amamentação, segundo o relato das participantes, como um ato de

Amor, carinho... (E4)

Essa imagem encaixa-se em todas as suas representações de boa mãe, produzidas e compartilhadas. Nessa conformação, ao reafirmarem a quantidade de leite, afirmam a quantidade de "amor": ter leite e amamentar (boa mãe) corresponde a ser uma mãe que ama.

Eu tenho! Que nem agora, ela [olha para a bebê que está no colo mamando] tá (sic) com um ano e oito, às vezes quando ela brinca demais, tipo ela fica uma hora longe, o peito já começa a escorrer. E ela já tá (sic) com um ano e oito, né? [...] Eu espero que ela mame um pouco mais até uns 2, 3 aninhos, mas sim, eu tenho bastante leite! (E5)

Em oposição à Mulher-mãe com Leite está a Mulher-mãe Seca, conforme segue. 


\section{Mulher-mãe Seca}

Os sistemas de representação, segundo Meyer (2003), quando posicionam seres humanos como mulheres, mães, nutrizes e/ou cuidadoras de diferentes tipos, ao proporcionarem respostas que possibilitam a elas entender aquilo que são ou devem fazer enquanto mães ou, ainda, ao operarem a equivalência entre o ser mãe e a prática da amamentação, ou entre maternidade e amor desmedido ou abnegado, conformam os corpos e as identidades desses sujeitos. Esse posicionamento incide sobre os processos de definições de boa mãe (responsável) ou de má mãe (relapsa), e dos tipos de vínculos entre mãe e filho (adequados ou inadequados) que ocorrem dentro ou no entorno dos programas de saúde. Portanto, têm efeitos muito concretos nas vidas das pessoas e dos grupos de mulheres que neles são definidos, posicionados e mobilizados.

Nesse sentido, esta subcategoria contempla as representações das mulheres que não amamentam, denominadas pela força da expressão Mulher-mãe Seca: que não tem ou não dá o leite materno, ou seja, aquela que não dá ou não tem o amor de mãe. Nesse contexto histórico-sociocultural, em relação às mulheres que amamentam, as que não amamentam são percebidas pelas participantes como

São mais secas! (E4)

São mais estúpidas com a criança! (E6)

São mães que não amam e/ou sabem amar.

\section{Mulher-mãe Frágil}

O núcleo de sentido Mulher-mãe Frágil se deu a partir da revelação dos conflitos e das questões de vulnerabilidade vivenciadas pelas participantes, tais como: ficar em casa cuidando dos filhos e da família ou voltar a trabalhar; retornar ao trabalho e perder e/ou prejudicar o crescimento dos filhos; ou ainda, ajustar-se às regras e horários da empresa ou fazer valer seus direitos publicizados na Cartilha. Os conflitos que circundam as mulheres e as empresas são, em especial, as situações em que as participantes se reconhecem mais frágeis, pois implicam relações de poder que acabam fazendo com que essas mulheres sempre fiquem em estado de alerta, à espera da punição ou demissão, causando sofrimento, culpa e até problemas de saúde. Além disso, as participantes sabem dos seus direitos como mulheres trabalhadoras que amamentam, mas também sabem que seus patrões não necessariamente os cumprem.

Eu acredito que esta questão de Cartilha e esclarecimento tem que ser dado às empresas [todas falam ao mesmo tempo que também concordam], com as patroas, porque eu vou te dizer assim... que embora eles saibam os teus direitos, eles fazem como se não existisse aquilo. [...] A Cartilha te mostra que tu tem todos esses direitos aqui [levantando a Cartilha impressa], mas a empresa ou a patroa não vai abrir mão desse tempo, ela se faz de ouvidos mortos. (E2)

Isso evidencia suas percepções sobre sua posição de vulnerabilidade diante das orientações da Cartilha que estimula o diálogo funcionária-patrão, e, segundo elas, pouco ou nada leva em consideração as condições do seu mundo objetivo.

\section{Mulher-mãe Empoderada}

Em oposição à Mulher-mãe Frágil está a Mulher-mãe Empoderada. Segundo as entrevistadas, essa mulher ideal, projetada na/pela Cartilha como articulada, capaz de estabelecer diálogos equilibrados com patrões e colegas de trabalho não expõe os conflitos e as questões de vulnerabilidade vivenciadas por elas. Portanto, não se reconhecem nessa mulher idealizada pela Cartilha. 
Esse não reconhecer-se na Mulher-mãe Empoderada (mulher ideal representada pela Cartilha) e o reconhecer-se na Mulhermãe Frágil ocorre quando as entrevistadas identificam a falta de cuidado na produção da Cartilha, que falha ao não representar a diversidade de profissões da mulher-mãe que amamenta nos dias de hoje, como exemplificado por elas:

É que nem todos trabalham num escritório! (E5)

É, eu trabalho com faxina! (El)

Assim, explicitaram que em seu grupo a Mulher-mãe Empoderada não existia.

\section{Informar para responsabilizar}

Com base nos relatos das entrevistadas, problematizamos a Cartilha em perspectiva de ser comunicação pública, pois que se trata de material de comunicação produzido e veiculado pelo Ministério da Saúde. As análises revelam que a Cartilha falha em sua perspectiva de ser comunicação pública, pois que se afasta do mundo objetivo das entrevistadas à medida que fala para outras mulheres: as empoderadas. Por não se sentirem representadas pela mulher apresentada na Cartilha e nem se sentirem "ouvidas", classificaram a Cartilha como "superficial", e revelaram-se insatisfeitas com a falta de concretude das ações do Ministério da Saúde e, por extensão, do Estado:

Eles estão deixando muito a desejar, eles só falam, é uma coisa só escrita, não énada, eles não vão atrás, eles não tentam informar, é uma coisa que é só escrita na Cartilha, se a mãe ler tá (sic) bom! (E5)

Complementarmente, e para que possamos avançar na problematização apresentamos a Figura 1 que sintetiza as representações da mulher-mãe percebidas pelas participantes. Além disso, procuramos distribuir essas representações da figura de modo a também evidenciar graficamente o lugar positivo ou negativo que ocupam.

Figura 1: Representações da Mulher-mãe materializadas na/pela Cartilha conforme as participantes².

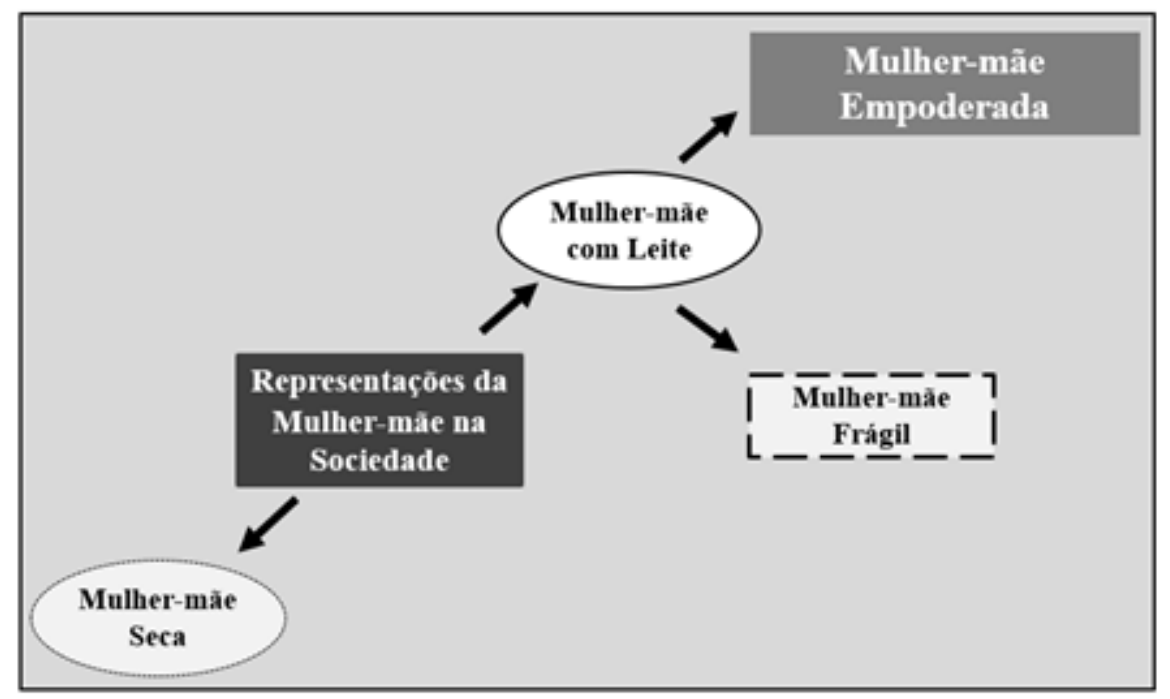

Fonte: Silveira, 2018.

Recuperarmos, aqui, o fato de que em relação às representações da mulher-mãe na sociedade, a Mulher-mãe Secafoi historicamente silenciada ou negativamente qualificada nos materiais educativos de saúde que trataram do aleitamento materno, o que fez com que ela fosse classificada como inferior nas representações da mulher-mãe compartilhadas pela sociedade. Além disso,

2 Para ler a figura: setas com orientação ascendente indicam sentidos positivos para a subcategoria e núcleo de sentido; setas com orientação descendente, indicam sentidos negativos. 
conforme pudemos depreender das análises, as próprias mulheres tratam de se distinguir dessa mulher que é vista como uma mãemá. E, para se distinguirem da Mulher-mãe Seca, acionaram o critério do determinismo biológico de ter leite, o mesmo que é empregado pela sociedade como um todo. Até porque, como consequência, isso acaba legitimando a Mulher-mãe com Leitecomo a boa mãe, isto é, aquela que não só possui "o melhor alimento" para seu filho, como também carrega a total responsabilidade de criar cidadãos saudáveis, não levando em consideração os meios que essa mulher tem para isso.

Contudo, conforme evidenciamos, nem todas essas mulheres têm lugar na Cartilha, como "material" de comunicação pública. Isso se deve, dentre outras coisas, à falta de um debate ampliado que dê voz à diversidade de mulheres-mães e considere suas necessidades objetivas. Essa conformação tende a fazer com que a Mulher-mãe com Leite ao invés de se tornar a mulher materializada na/pela Cartilha seja fracionada em duas representações: a Mulher-mãe Frágil e a Mulher-mãe Empoderada. Assim, a Cartilha perde aderência com as mulheres "frágeis", uma vez que não se reconhecem nessa representação de "empoderadas"; essas mulheres assumem a responsabilidade por ter leite e querer amamentar, mas se percebem impotentes frente às relações de poder que materializam quando do seu retorno aos postos de trabalho fora de casa.

Nesse sentido, se é fato que a Cartilha dá visibilidade às leis, também é que as entrevistadas sabem dos seus direitos. Entretanto, em seu mundo objetivo, sabem que tendem a ser percebidas como "peso" para quem as contrata e que podem ser demitidas por isso. Essa questão de fundo não é tratada na Cartilha, não recebe publicidade/visibilidade para gerar debate e crítica; sequer é abordada de modo superficial. Ao não atentar para isso, a Cartilha inclina-se a reforçar o autorreconhecimento dessas mulheres como Mulher-mãe Frágil. Ao mesmo tempo, afirmam que a Mulher-mãe Empoderada apresentada na Cartilha (idealizada pelo Ministério da Saúde) não dá conta da realidade das mulheres trabalhadoras que amamentam em nosso país, mas que serve como estratégia, uma vez que as campanhas servem para alertar acerca dos sintomas, dos riscos etc., fazendo com que, nessa operação (de informação e alerta ao público), o Estado, por ter em alguma medida cumprido com a sua parte, transfira a sua responsabilidade para o indivíduo, no caso, para elas.

Ressaltamos o despropósito dessa estratégia (com características de 'crueldade') em transferir a tarefa de sensibilização das empresas/patrões à Mulher-mãe Frágil, como se ela fosse responsável por ações que o próprio Ministério da Saúde não alcança. E, mais, apresenta isso de maneira cínica, como um material que tem por objetivo "dar algumas respostas" a essas mulheres quando, na prática, apenas lança diversas informações e orientações de "como fazer" sem se preocupar com a realidade socioeconômica dessas mulheres e, tampouco, trazer a suas perspectivas como sujeitos dessa prática. As mulheres buscam ter voz, protagonizar as Campanhas de Aleitamento Materno; uma Cartilha que se torna "uma coisa só escrita", em momento nenhum pode ser considerada um qualificado material de comunicação pública.

\section{CONSIDERAÇÕES}

Ao problematizarmos os processos de comunicação pública realizados pelo Ministério da Saúde, a partir das representações da mulher-mãe na Cartilha para a mulher trabalhadora que amamenta, sob a perspectiva das participantes do Estudo LINDABrasil, importa reafirmarmos que as representações da mulher-mãe compartilhadas na sociedade estão impregnadas do reducionismo biológico marcado pela incapacidade de lidar com o conflito que se estabelece para a mulher-mãe entre 0 querer e o poder amamentar. Nos materiais educativos em prol da causa, essa incapacidade silenciou historicamente a Mulher-mãe que, por alguma razão, não amamentava e, em sentido mais grave, desqualificou-a como Mulher-mãe Seca.

Com esse pano de fundo, a Cartilha se orienta, invariavelmente, para informar a mulher sobre os direitos e as vantagens em ofertar o leite materno a seu filho e por responsabilizá-la pelos resultados futuros. Essa lógica de informar para responsabilizar procura modular o comportamento da Mulher-mãe com Leite em favor da amamentação, imputando-lhe 
culpa pelo desmame precoce, que é associado de forma direta a agravos para a saúde de seu filho. Assim, nesse discurso predomina o enfoque na saúde e bem-estar da criança, ficando a perspectiva da Mulher-mãe Frágil - com seus contextos, necessidades e vulnerabilidades - fora do foco dos sentidos que embasam os discursos oficiais sobre aleitamento materno no país, que, a partir da idealização da Mulher-mãe Empoderada, torna a Cartilha apenas "letras" sem sentido, e faz com que a comunicação pública realizada pelo Ministério da Saúde permaneça míope, sem enxergar fidedignamente as mulheres trabalhadoras que amamentam.

\section{REFERÊNCIAS}

ALMEIDA, João Aprígio Guerra de. Amamentação: um híbrido natureza-cultura. 1998. Tese (Doutorado em Saúde da Criança e da Mulher) - Instituto Federal Fluminense, Rio de Janeiro, 1998.

BADINTER, Elisabeth. O conflito: a mulher e a mãe. Rio de Janeiro: Record, 2011.

BALDISSERA, Rudimar. Comunicação organizacional: o treinamento de recursos humanos como rito de passagem. São Leopoldo: Unisinos, 2000.

BARDIN, Laurence. Análise de Conteúdo. São Paulo: Edições 70, 2011.

BOSI, Maria Lúcia Magalhães; MACHADO, Márcia Tavares. Amamentação: um resgate histórico. Cadernos da Escola de Saúde Pública do Ceará, Fortaleza, v.1, n.1, p.17-25, jul./dez. 2005. Disponível em: https://goo.gl/Mxn4Wj. Acesso em: 16 ago. 2016.

BRASIL. Ministério da Saúde. Cartilha para a mulher trabalhadora que amamenta. 2. ed. Brasília, DF, 2015.

COSTA, Jurandir Freire. Ordem Médica e Norma Familiar. 4. ed. Rio de Janeiro: Graal, 1999.

ESTEVES, João Pissarra. Sociologia da Comunicação. Lisboa: Fundação Calouste Gulbenkian, 2011.

GIL, Patrícia Guimarães; MATOS, Heloiza. Quem é o cidadão na comunicação pública? Uma retrospectiva sobre a forma de interpelação da sociedade pelo Estado em campanhas de saúde. In: MATOS, H. (org.). Comunicação Pública: interlocuções, interlocutores e perspectivas. São Paulo: ECA/USP, 2013. Disponível em: https://goo.gl/wFpKwZ. Acesso em: 11 jun. 2016.

GOMES, Wilson. Apontamentos sobre o conceito de esfera pública política. In: MAIA, Rousiley; CASTRO, Maria Céres Pimenta Spínola (org.). Mídia, esfera pública e identidades coletivas. Belo Horizonte: Editora UFMG, 2006.

HALL, Stuart. Cultura e representação. Rio de Janeiro: PUC-Rio: Apicuri, 2016.

KALIL, Irene Rocha. De silêncio e som: a produção de sentidos nos discursos oficiais de promoção e orientação ao aleitamento materno brasileiros. 2015. 244 f. Tese (Doutorado em Informação e Comunicação em Saúde) - Fundação Oswaldo Cruz, Instituto de Comunicação e Informação Científica e Tecnológica em Saúde, Rio de Janeiro, 2015.

MATOS, Heloiza. A comunicação pública na perspectiva da teoria do reconhecimento. In: KUNSCH, Margarida Maria Krohling. Comunicação pública, sociedade e cidadania. São Caetano do Sul: Difusão, 2011. 
MEYER, Dagmar Estermann. Educação, saúde e modos de inscrever uma forma de maternidade nos corpos femininos. Movimento, Porto Alegre, v. 9, n. 3, p. 33-58, 2003. Disponível em: https://goo.gl/AU2Rpc. Acesso em: 13 fev. 2017.

NAKANO, Ana Márcia Spanó. O aleitamento materno no cotidiano feminino. 1996. Tese (Doutorado em Enfermagem) Universidade de São Paulo, Ribeirão Preto, 1996.

PITTA, Aurea Maria da Rocha. Por uma política pública de comunicação em saúde. Saúde e Sociedade, São Paulo, v.11, n.1, p.85-93, 2002. Disponível em: https://goo.gl/EjVtUR. Acesso em: 1 nov. 2017.

SARTOR, Basilio Alberto; BALDISSERA, Rudimar. A noção de interesse público e a perspectiva da comunicação. In: ROSÁRIO, Nísia Martins do; SILVA, Alexandre Rocha da (org.). Pesquisa, Comunicação, Informação. Porto Alegre: Sulina, 2016.

SCHMIDT, Maria Inês etal. Lifestyle Intervention for diabetes prevention after pregnancy (LINDA-Brasil): study protocol for a multicenter randomized controlled trial. Disponível em: goo.gl/mAqDek. Acesso em: 19 fev. 2017.

SILVA, Antônio Augusto Moura da. Amamentação: fardo ou desejo? estudo histórico-social dos saberes e práticas sobre aleitamento na sociedade brasileira. 1990. Dissertação (Mestrado em Medicina Preventiva) - Faculdade de Medicina de Ribeirão Preto, Universidade de São Paulo, Ribeirão Preto, 1990.

SILVEIRA, Amanda Braga. Comunicação Pública e Campanhas de Aleitamento Materno: representações da mulher-mãe materializadas na/pela Cartilha para a mulher trabalhadora que amamenta do Ministério da Saúde. 2018. Dissertação (Mestrado em Comunicação e Informação) - Faculdade de Biblioteconomia e Comunicação, Universidade Federal do Rio Grande do Sul, Porto Alegre, 2018.

Artigo recebido em 30-11-2019 e aprovado em 23-11-2020 